\title{
Early diagnosis of bronchial stent related malignant respiratory fistulas
}

\section{To the Editor:}

The stent related bronchoesophageal fistula recently published by TULLEKEN et al. [1] is a relative rare sequelae of this new management. This stent has been used to control postoperative stenosis of reconstructed left main bronchus rupture after blunt thoracic injury.

Congratulations for the early recognition of the airfilled oesophagus as a sign of fistula in the diagnostic procedure. I add a short comment on the other, more frequent types of fistulas.

The increased number of oesophagorespiratory fistulas, as a side-effect of radiochemotherapy for the palliation of inoperable bronchoesophageal malignances, has increased in the past decade. I had the opportunity to treat 10 patients (1990-2000) with such complications, using a cuffed-funnel oesophageal tube [2].

Stent implantation, is increasingly used by us to assure airway patency in advanced tracheobronchial carcinoma with secondary oesophageal invasion. Therefore, we routinely perform barium meal swallowing which is the basic, most useful examination to detect respiratory-fistula formation. This preventive examination may detect the onset of fistula and combined with bronchoscopy it allows prompt adequate therapeutic measures. In this way in three cases of stent related early fistulae, successful fistula obliteration and restoration of swallowing were obtained by a secondary oesophageal intubation using a personal technique [3] and tube.

\section{Kotsis*, Z. Pápay}

*Thoracic Surgical Clinic, Korányi National Pulmonology Insitute and "Bronchology, Semmelwies University, H-1529 Budapest, Pihenö u. 1., Hungary.

\section{References}

1. Tulleken JE, Van Minnen CA, Waterbolk TJW, et al. A 17 -yr-old boy with productive cough and progressive dyspnoea. Eur Respir J 2000; 16: 1023-1024.

2. Kotsis L, Zubovits K, Vadász P. Management of malignant tracheoesphageal fistulas with the cuffed funnel tube. Ann Throac Surg 1997; 64: 355-358.

3. Kotsis L, Zubovits K, Helier Z. Particular aspects and limits of palliation in secondary malignant esophageal structures. Dis Esoph 1997; 10: 238-242. 